\title{
Creating Faculty BuY-In: Leadership Challenges in IMPLEMENTING CEAB GRADUATE ATTRIBUTES
}

\author{
Govind Gopakumar, Deborah Dysart-Gale, Ali Akgunduz \\ Faculty of Engineering and Computer Science, Concordia University, Montreal, Canada \\ govind.gopakumar@concordia.ca
}

\begin{abstract}
In 2009 the Canadian Engineering Accreditation Board (CEAB) announced its intention requiring all undergraduate engineering programs in Canada to utilize twelve graduate attributes for assessing the capacities of its students. In response, engineering faculties across the country have been experimenting with creating processes that incorporate these graduate attributes as a means to stimulate program improvement to achieve curricular and program innovation. Many of the support resources (like the inter-university collaboration EGAD, for example) have focused largely in three directions - definitional, programmatic and information management challenges faced by different engineering programs.

Less attention has been given to identifying and addressing leadership challenges faced by faculty administrators in piloting curricular and programmatic changes such as the CEAB graduate attributes. We argue that these challenges result from fundamental features of university educational culture: faculty members place great value upon autonomy in their workplace, and likewise expect a high degree of intellectual independence in designing courses. The introduction of CEAB attributes, together with the mandated changes they will bring to course design, is perceived by faculty members as an external imposition. Such a perception we suggest introduces some scepticism in the faculty about its efficacy leading to a disengagement from the change process. Thorough attention to these cultural factors impacting on graduate attributes adoption is crucial to the implementation of successful curriculum development. Describing these challenges in detail, this paper will outline some pathways that can circumvent these impediments to curricular innovation.
\end{abstract}

Keywords: CEAB, accreditation, leadership, faculty, buyin.

\section{INTRODUCTION}

This is an exploratory paper that seeks to understand the cultural nature of the challenges that faculty administrators face in implementing an attribute-based outcomes assessment process to evaluate undergraduate engineering education programs. The primary motivation for this paper is the recent adoption by CEAB of twelve graduate attributes to assess engineering programs in Canada.

The paper is structured as follows: the second section of this paper describes some key aspects of the process of assessment proposed by CEAB. In the next section, we focus on the EGAD project - a collaborative interuniversity initiative that is a valuable resource for engineering programs seeking to re-align their program offerings with the new CEAB guidelines. Despite the existence of resources like the EGAD project, this paper identifies leadership and administrative challenges for program re-orientation as a notable gap. In section four and five of the paper, we develop the concept of a faculty cultural matrix and associated leadership challenges as a means to shed some light on this relatively unexplored domain of outcomes assessment. This paper concludes with some final thoughts on a way forward for faculty administrators.

\section{OUTCOME-BASED GRADUATE ATTRIBUTES}

Engineering education programs in universities and other tertiary education institutions, in many countries around the world, have to demonstrate the quality of their curricular and programmatic offerings by passing the accreditation process. Accreditation in this context is understood as a "process of recognition of an educational institution or educational programmes based on standard qualifications and criteria" [1]. While accreditation seeks to serve several goals [1], the predominant purpose of accreditation is to "assure prospective students and the public that graduates of an accredited institution or program have achieved a minimum level of competence in their chosen field of study" [2]. In meeting these explicit quality guarantee as well as public accountability 
objectives, different countries have experimented with different architectures to conduct the process of accreditation. Thus for example in USA, accreditation is steered by the American Board of Engineering and Technology (ABET) as a "voluntary, peer review process conducted by non-governmental organizations usually associations of educational institutions or professional societies" [2]. In Canada, on the other hand, accreditation is attached to the "closed" and statutory [3] system of professional practice and therefore is mandatory and quasi-governmental. Since 1965, CEAB has guided the accreditation of engineering programs in Canada. CEAB is an entity constituted by Engineers Canada, itself a national organization constituted solely by the twelve provincial and territorial associations that govern the practice of the engineering profession in the country [4].

In $2009 \mathrm{CEAB}$ changed the accreditation process from a predominantly inputs-based to an outputs-oriented one. In making this shift CEAB identified twelve outcomes that must be reflected in the attributes a graduate of an accredited program possesses. The twelve graduate attributes identified include:

1. A knowledge base for engineering,

2. Problem analysis,

3. Investigation,

4. Design,

5. Use of engineering tools,

6. Individual and team work,

7. Communication skills,

8. Professionalism,

9. Impact of engineering on society and the environment,

10. Ethics and equity,

11. Economics and project management, and

12. Life-long learning.

Although till June 2015 the CEAB has decided not to make graduate attributes enforceable in accreditation decisions, many engineering faculties have adopted tentative directions to face the challenge of assessing CEAB graduate attributes within their curricular and programmatic offerings. Papers presented at recent Canadian Engineering Education Association (CEEA) annual conferences in 2011 and 2012 have many samples of such efforts. Some of these papers describe the definitional challenges $[5,6,7]$, programmatic challenges [8], and challenges due to the intersection with UDLES $[9,10]$.

\section{THE EGAD PROJECT AND ITS APPROACH}

Given the comprehensive program and curricular reorientation anticipated through the shift towards an outcome-based assessment process, it is little wonder that different faculties of engineering in the country have had to dedicate time and sustained effort to conceptualize new assessment strategies. In doing this many have had to rely on external resources that will help them with the definitional, programmatic, and informational challenges associated with incorporating the outcomes attributes into their assessment routines. One key resource for faculties is the Engineering Graduate Attribute Development (EGAD) Project. EGAD was initiated as a project sponsored by $\mathrm{CEAB}$ and the National Council of Deans of Engineering and Applied Science with the collaborative involvement of engineering educators and educational developers from across Canada [11].

The EGAD project of outcomes-based curriculum development recognizes four fundamental tenets [12]:

a. An outcomes-based process of curriculum development must be one of continuous and sustainable improvement

b. The achievement of outcomes is a shared responsibility of faculty and students

c. There is a culture of autonomy and academic freedom within curriculum development in higher education.

d. It proposes a scholarly approach that is facultydriven, data-informed, and literature-supported.

These tenets seek to clarify some specific modalities of curriculum development - a program of continuous and sustainable improvement that is faculty-driven, datainformed and literature supported. This denotes that this process stimulates an examination of curriculum that is ongoing and rigorous [13]. In other words, the EGAD project seeks to utilize the opportunity provided by CEAB to foster two major transformations in curriculum examination - first, it is a continuous process rather than an episodic, once-in-a-while process; and second, it proceeds with a rigorous and critical study of evidence from student learning, faculty perception and existing scholarship before making a change. These processspecific modalities of the EGAD project forms the kernel of its five-step guide to curriculum development -1 . program evaluation; 2 . curriculum mapping; 3 . identifying and collecting data on student learning; 4 . analyzing and interpreting data; 5. data-informed curriculum development. This five-step guide forms the basis for a strategy to restructure curriculum at several different faculties of engineering in the country $[8,14]$. In doing so, these approaches have focused primarily on the definitional, programmatic, and information management challenges of the task.

However, in addition to the process modalities of these tenets, EGAD recognizes that any process of curriculum overhaul happens within the unique inter-personal and collective dynamics of a higher educational institution. Thus EGAD states that there is a "culture of autonomy and academic freedom within curriculum development in 
higher education" [12]. The existence of this culture of autonomy has a powerful bearing on the dynamics of curricular change especially by shaping structures of decision-making and leadership, and by influencing administrative priorities, pathways, and practices. Acknowledging the crucial influence exerted by this cultural specificity some recent papers have tried to compare managerial structures and processes [14] and leadership best practices [15] in attributes-based curricular restructuring. Despite this very little attention has been paid to understanding the leadership and administrative challenges posed by the prevalent culture of autonomy and freedom in universities and other institutions of higher education.

\section{CULTURAL MATRIX OF A FACULTY}

Understanding the leadership challenges involved in curricular and program re-orientation requires an appreciation for the cultural matrix that guides the actions of individuals and groups of people within the organizational setting of a faculty. The cultural matrix of a faculty or university is composed of "deeply embedded and shared values, beliefs and norms" [16, 17]. The presence of these widely held values and norms shape the practices, beliefs and assumptions that people possess from working within an organization. The uniqueness of a faculty or academic culture is that it is the product of multiple intersecting cultural domains [18, 19]. The existence of these multiple cultural domains can be related to the long history (traced back to medieval European guilds) that universities possess in Western society. This long historical presence of universities has made them key players as well as objects of socio-economic transformation. As a result, universities have become receptacles of several, often contradictory, value and belief systems. These multiple and simultaneous cultural pressures expose individuals located at different levels to a different mix of cultural influences.

Following Austin we understand the faculty culture matrix in this paper as a product of the intersection of four different cultural influences [19] -

a. Culture of the academic profession or a collegial culture marked by values derived from the nature of the profession that faculty members are part of. As a profession devoted to the production, distribution and generation of knowledge, core values such as intellectual autonomy, commitment to serve society are internalized by members. In addition, these core values are often embedded within practices such as peer review in committee, tenure, and service to the university;

b. Culture of the academy as an organization or managerial culture signifies the administrative and bureaucratic aspects of governing an academic institution to serve purposes of public oversight, standardization, transparency or accreditation;

c. Culture of the discipline or disciplinary culture relate to the values arising from the specific characteristics of the disciplinary formations faculty is affiliated with. These values and belief systems vary depending upon the nature of the discipline (science/engineering vs humanities) or the degree of connection the members of the faculty have with their parent disciplines; and

d. Culture of institutional types or institutional culture is dependent on the specific values and norms of their parent institution arising from its history, its role in its society, societal and national influences.

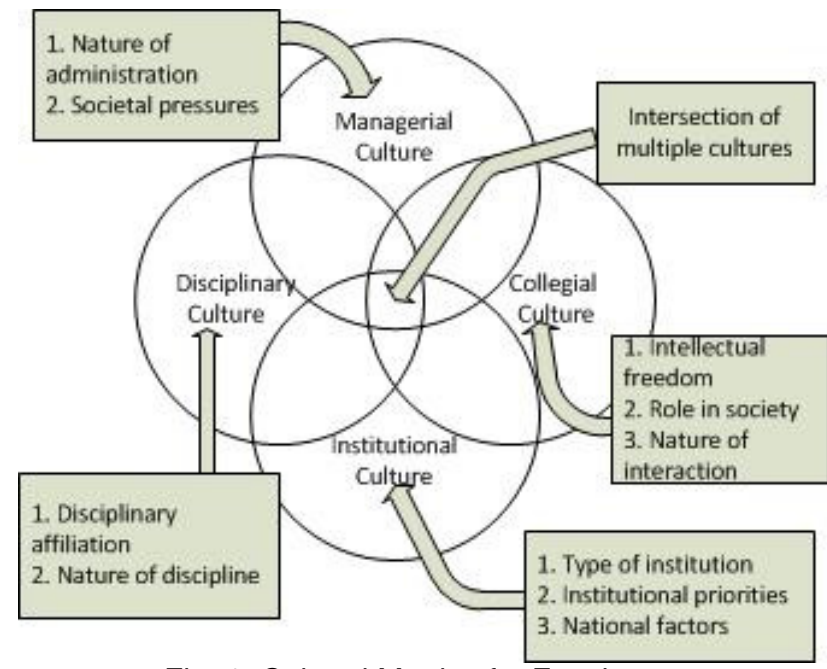

Fig. 1. Cultural Matrix of a Faculty.

Figure 1 displays the cultural matrix of a faculty constituted by four cultures. The interaction of each of these cultures is unique within specific institutions as well as faculties within these institutions. So any administrator or team leader seeking to transform or re-orient programs will need to assess the cultural matrix in their faculties before adopting change strategies.

\section{LEADERSHIP CHALLENGES}

A cultural matrix poses some unique challenges for an individual who seeks to change how a faculty performs its role. An important reason that the cultural matrix for a faculty is a challenge because the multiple sources for the matrix intersect and interact in complex ways to shape the behavior of individual faculty members. Thus the nature of the challenge a change-maker faces cannot easily be known without a deliberate process of assessing the specificities of their particular cultural matrix. However, it is possible to propose some generic challenges that an 
entrenched faculty culture matrix can pose. While the specific mix of challenges varies from institution to institution, elements in the faculty culture create the circumstances for some generic challenges. This is all the more true for an engineering faculty where it is possible to identify some specific generic influences that the collegial, managerial, disciplinary, and institutional cultures of the faculty exert on individuals. An outcomes assessment exercise has to contend with some of the challenges posed by the cultural matrix of an engineering faculty [20]. Although based on the outcomes assessment exercise in USA, [20] lists some key challenges posed by faculty culture in engineering. Table 1 categorizes these challenges according to their cultural origin.

Table 1: Leadership challenges from a cultural matrix

\begin{tabular}{|c|c|}
\hline $\begin{array}{c}\text { Elements of } \\
\text { Faculty Culture }\end{array}$ & Leadership Challenges \\
\hline Collegial Culture & $\begin{array}{l}\text { 1. Respect for individualism and } \\
\text { autonomy } \\
\text { 2. Suspicious of 'jargon-laden' } \\
\text { language }\end{array}$ \\
\hline $\begin{array}{l}\text { Managerial } \\
\text { Culture }\end{array}$ & $\begin{array}{l}\text { 1. Academic rewards not } \\
\text { congruent with assessment. } \\
\text { 2. Vertical communication not } \\
\text { effective } \\
\text { 3. Profile of senior faculty } \\
\text { administrators }\end{array}$ \\
\hline $\begin{array}{l}\text { Disciplinary } \\
\text { Culture }\end{array}$ & $\begin{array}{l}\text { 1. Indifference to strategic } \\
\text { planning efforts. } \\
\text { 2. Skeptical of outside opinion } \\
\text { 3. Strong orientation towards } \\
\text { disciplinary excellence }\end{array}$ \\
\hline $\begin{array}{c}\text { Institutional } \\
\text { Culture }\end{array}$ & $\begin{array}{l}\text { 1. Resistant to change } \\
\text { 2. Resistance to 'customer } \\
\text { oriented' thinking } \\
\text { 3. Canadian/provincial influences } \\
\text { on institutional administration }\end{array}$ \\
\hline
\end{tabular}

The challenges listed in Table 1 are generic in nature. The particular nature of challenges that present themselves to specific university administrators engaged in the outcomes assessment process is related to the onthe-ground settings at each university.

\section{CONCLUSION}

CEAB has recently adopted a summative outcomesbased accreditation process [21] for evaluating the standards of undergraduate engineering education in Canada. CEAB has specified twelve attributes that need to be satisfied through the outcomes assessment process. Given the paradigmatic nature of the shift in assessment, engineering faculties across the country face significant challenges in incorporating the attributes-based outcomes assessment process. This paper has proposed that some of the nature of the challenges associated with this shift arise from the nature of the unique cultural matrix shaping the behavior, interactions and actions of individual members in any engineering faculty. This paper suggests that these challenges can be related to the intersection of the collegial culture, managerial culture, disciplinary culture and institutional culture at their parent institution. In creating faculty buy-in for the proposed changes in assessment, it is important for leaders of assessment to gauge the unique mix of leadership challenges that their institution creates before directing their energies at curriculum and program development in the faculty. Although a cultural appraisal exercise would be useful to understand the sources of resistance, given the entrenched nature of the cultural matrix, there are no silver bullets to institutional change. Faculty leaders should be patient, and be prepared for a long, and potentially tedious, process of curricular and program transformation.

\section{References}

[1] Arun Patil and G. Codner, "Accreditation of engineering education: review, observations and proposal for global accreditation," European Journal of Engineering Education, vol. 32, no. 6, pp. 639-651, 2007.

[2] John W. Prados, George D. Peterson, Lisa R. Lattuca, "Quality Assurance of Engineering Education through Accreditation: The Impact of Engineering Criteria 2000 and its Global Influence," Journal of Engineering Education, vol. 94, no. 1, pp. 165-184, 2005.

[3] Gordon C. Andrews, Canadian Professional Engineering and Geoscience: Practice and Ethics. Toronto: Nelson Education, 2009 (4th ed.), 428 pp. \{ISBN: 978-0-17644134-0\}

[4] Engineers Canada, Canadian Engineering Accreditation Board - Accreditation Criteria and Procedures 2012. Ottawa, Canada: Canadian Council of Professional Engineers (CCPE), 2012, 114 pp. \{ISSN- 1708-8054\} Available as of April 23, 2013 from

http://www.engineerscanada.ca/files/w Accreditation_Criteria Procedures_2012.pdf

[5] Said M. Easa, and Mohammad Lachemi, "Assessing CEAB Graduate Attributes at Ryerson University: Framework and Ingredients for Success," in Proc. CEEA Canadian Engineering Education Conf., CEEC11, Andy Fisher (ed.) (St. John's, NL; 6-8 June 2011), 1 pp., 2011.

[6] Darlene Spracklin-Reid, and Andrew Fisher, "CourseBased Learning Outcomes as the Foundation for Assessment of Graduate Attributes," in Proc. 2012 Canadian 
Engineering Education Association (CEEA 12) Conf., Witold Kinsner (ed.) (Winnipeg, MB; 17-20 June 2011), 3 pp., 2012.

[7] Sandra Ingram, Jillian S. Cicek, and Nariman Sepehri, "The Attribute Assessment Process at the University of Manitoba," in Proc. 2012 Canadian Engineering Education Association (CEEA 12) Conf., Witold Kinsner (ed.) (Winnipeg, MB; 17-20 June 2011), 7 pp., 2012.

[8] Susan McCahan and Lisa Romkey, "Update on the University of Toronto Graduate Attribute Process," in Proc. 2012 Canadian Engineering Education Association (CEEA 12) Conf., Witold Kinsner (ed.) (Winnipeg, MB; 17-20 June 2011), 6 pp., 2012.

[9] Warren Stiver, "CEAB's Graduate Attributes and Ontario's UUDLEs," in Proc. CEEA Canadian Engineering Education Conf., CEEC11, Andy Fisher (ed.) (St. John's, NL; 6-8 June 2011), 4 pp., 2011.

[10] Jessica Harris, Alan Steele, and Donald Russell, "Progress on Defining the CEAB Graduate Attributes at Carleton University," in Proc. CEEA Canadian Engineering Education Conf., CEEC11, Andy Fisher (ed.) (St. John's, NL; 6-8 June 2011), 5 pp., 2011.

[11] Brian Frank, Susan McCahan, K. Christopher Watts, Susan Fostaty-Young, Peter Ostafichuk, Peter Wolf, and Nasser Saleh, "Engineering Graduate Attribute Development (EGAD) Project," in Proc. CEEA Canadian Engineering Education Conf., CEEC11, Andy Fisher (ed.) (St. John's, NL; 6-8 June 2011), 5 pp., 2011.

[12] EGAD, "Continuous Program Improvement Resources," Available as of April 24, 2013 from http://egad.engineering.queensu.ca/?page_id=829

[13] Peter Wolf, “A Model for Facilitating Curriculum Development in Higher Education: A Faculty-Driven, DataInformed, and Educational Developer-Supported Approach," New Directions in Teaching and Learning, vol. 2007, no. 112, pp. 15-20, 2007.
[14] James Kraupp, Brian Frank, Robert Brenman, Susan McCahan, Lata Narayanan, Peter Ostafichuk, Nariman Sepehri, and K. Christopher Watts, "A Comparison of Institutional Approaches to CEAB Graduate Attributes Requirements," in Proc. 2012 Canadian Engineering Education Association (CEEA 12) Conf., Witold Kinsner (ed.) (Winnipeg, MB; 17-20 June 2011), 7 pp., 2012.

[15] Said M. Easa, "One-year Outcome-Based Assessments at Ryerson University: Lessons and Best Practices," in Proc. 2012 Canadian Engineering Education Association (CEEA 12) Conf., Witold Kinsner (ed.) (Winnipeg, MB; 17-20 June 2011), 6 pp., 2012.

[16] Susan H. Frost and Paul M. Jean, "Making more of faculty culture: An experiment in building intellectual community," Tertiary Education and Management, vol. 6, no. 3, pp. 227$243,2000$.

[17] Claire H. Major, "Problem-based learning in General Education at Samford University: A Case Study of Changing Faculty Culture Through Targeted Improvement Efforts," The Journal of General Education, vol. 51, no. 4, pp. 235256, 2002.

[18] William H. Bergquist and Kenneth Pawlak, Engaging the Six Cultures of the Academy. San Francisco, CA: JosseyBass, 2008, 281 pp.

[19] Ann E Austin, "Understanding and Assessing Faculty Cultures and Climates," New Directions for Institutional Research, vol. 1994, no. 84, pp. 47-63, 1994.

[20] Robert K. Tener, "Outcomes Assessment and the Faculty Culture: Conflict or Congruence?” Journal of Engineering Education, vol. 88, no. 1, pp. 65-71, 1999.

[21] Joesph A. Shaewitz, "Outcomes Assessment in Engineering Education," Journal of Engineering Education, vol. 85, no. 3, pp. 239-246, 1996. 